University of South Carolina

Scholar Commons

$1-9-2006$

\title{
High-Pressure torsion-Induced Grain Growth in Electrodeposited Nanocrystalline $\mathrm{Ni}$
}

\author{
X. Z. Liao
}

A. R. Kilmametov

R. Z. Valiev

Hongsheng Gao

Xiaodong Li

University of South Carolina - Columbia, lixiao@cec.sc.edu

See next page for additional authors

Follow this and additional works at: https://scholarcommons.sc.edu/emec_facpub

Part of the Chemical Engineering Commons, and the Mechanical Engineering Commons

\section{Publication Info}

Published in Applied Physics Letters, Volume 88, Issue 2, 2006, pages \#021909-.

(C)Applied Physics Letters 2006, American Institute of Physics.

Liao, X. Z., Kilmametov, A. R., Valiev, R. Z., Gao, H., Li, X., Mukherjee, A. K., Bingert, J. F., \& Zhu, Y. T. (9 January 2006). High-Pressure torsion-Induced Grain Growth in Electrodeposited Nanocrystalline Ni. Applied Physics Letters, 88 (2), \#021909. http://dx.doi.org/10.1063/1.2159088

This Article is brought to you by the Mechanical Engineering, Department of at Scholar Commons. It has been accepted for inclusion in Faculty Publications by an authorized administrator of Scholar Commons. For more information, please contact digres@mailbox.sc.edu. 


\section{Author(s)}

X. Z. Liao, A. R. Kilmametov, R. Z. Valiev, Hongsheng Gao, Xiaodong Li, A. K. Mukherjee, J. F. Blingert, and Y. T. Zhu 


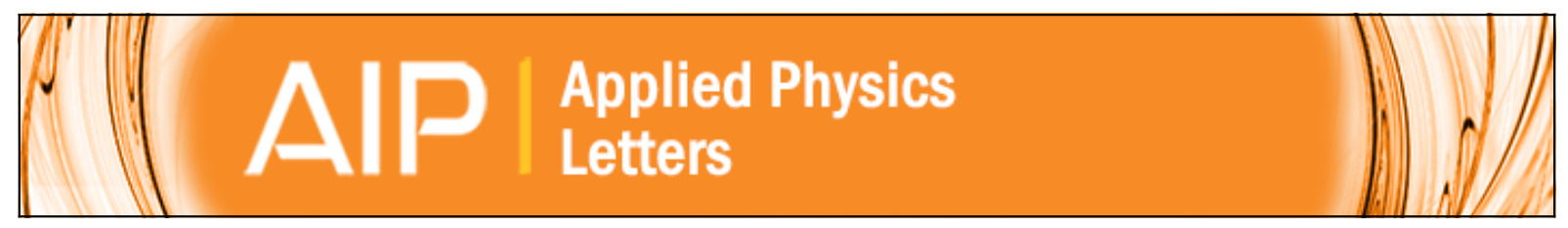

High-pressure torsion-induced grain growth in electrodeposited nanocrystalline $\mathbf{N i}$

X. Z. Liao, A. R. Kilmametov, R. Z. Valiev, Hongsheng Gao, Xiaodong Li, A. K. Mukherjee, J. F. Bingert, and Y.

T. Zhu

Citation: Applied Physics Letters 88, 021909 (2006); doi: 10.1063/1.2159088

View online: http://dx.doi.org/10.1063/1.2159088

View Table of Contents: http://scitation.aip.org/content/aip/journal/apl/88/2?ver=pdfcov

Published by the AIP Publishing

\section{Articles you may be interested in}

Grain growth kinetics and its effect on instrumented indentation response to nanocrystalline $\mathrm{Ni}$

AIP Conf. Proc. 1512, 180 (2013); 10.1063/1.4790970

X-ray diffraction of electrodeposited nanocrystalline nickel under high pressure

J. Appl. Phys. 105, 084311 (2009); 10.1063/1.3100189

Deformation-induced grain rotation and growth in nanocrystalline $\mathrm{Ni}$

Appl. Phys. Lett. 92, 011903 (2008); 10.1063/1.2828699

Grain-size effect on the deformation mechanisms of nanostructured copper processed by high-pressure torsion J. Appl. Phys. 96, 636 (2004); 10.1063/1.1757035

Model experiments for direct visualization of grain boundary deformation in nanocrystalline metals Appl. Phys. Lett. 83, 1441 (2003); 10.1063/1.1597417

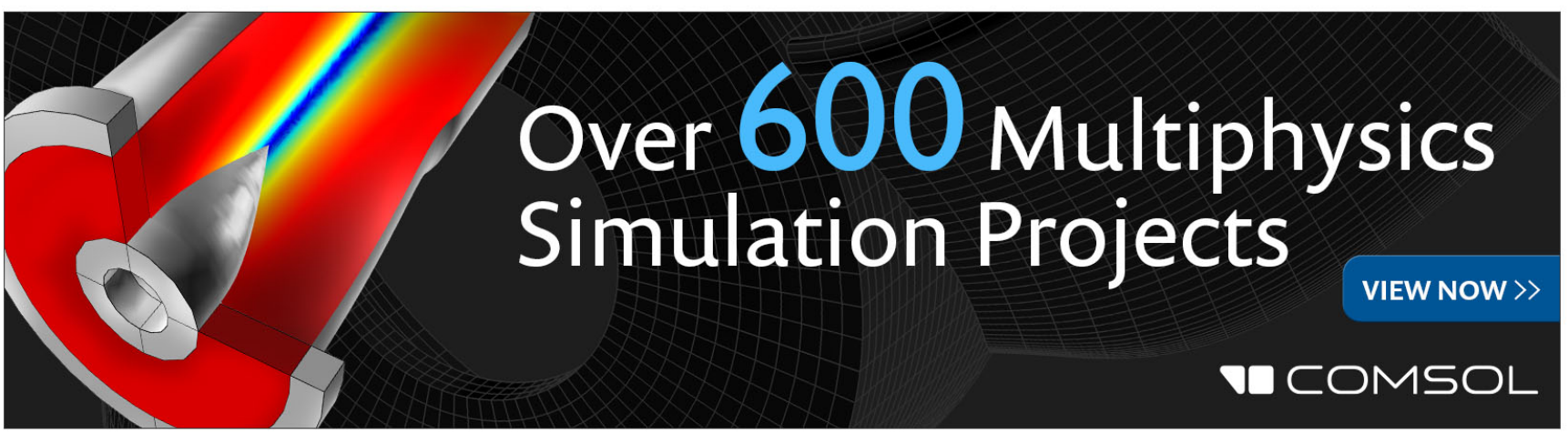




\title{
High-pressure torsion-induced grain growth in electrodeposited nanocrystalline $\mathrm{Ni}$
}

\author{
X. Z. Liao \\ The James Franck Institute, The University of Chicago, 5640 South Ellis Avenue, Chicago, Illinois 60637 \\ A. R. Kilmametov and R. Z. Valiev \\ Institute of Physics of Advanced Materials, Ufa State Aviation Technical University, K. Marksa 12, \\ Ufa 450000, Russia \\ Hongsheng Gao and Xiaodong Li \\ Department of Mechanical Engineering, University of South Carolina, Columbia, South Carolina 29208 \\ A. K. Mukherjee \\ Department of Chemical Engineering and Materials Science, University of California, Davis, \\ California 95616 \\ J. F. Bingert and Y. T. Zhu ${ }^{\text {a) }}$ \\ Materials Science and Technology Division, Los Alamos National Lab, Los Alamos, New Mexico 87545
}

(Received 10 August 2005; accepted 4 November 2005; published online 12 January 2006)

Deformation-induced grain growth has been reported in nanocrystalline (nc) materials under indentation and severe cyclic loading, but not under any other deformation mode. This raises an issue on critical conditions for grain growth in nc materials. This study investigates deformation-induced grain growth in electrodeposited nc Ni during high-pressure torsion (HPT). Our results indicate that high stress and severe plastic deformation are required for inducing grain growth, and the upper limit of grain size is determined by the deformation mode and parameters. Also, texture evolution suggests that grain-boundary-mediated mechanisms played a significant role in accommodating HPT strain. (C) 2006 American Institute of Physics. [DOI: 10.1063/1.2159088]

Recently, it was found that indentation had induced rapid grain growth in nanocrystalline (nc) $\mathrm{Cu}$ (Refs. 1 and 2) and $\mathrm{Al}^{3}$ Moreover, the grain growth was found faster at cryogenic temperatures than at room temperature, suggesting that the grain growth was driven primarily by stress, not by diffusion. ${ }^{2}$ Surprisingly, grain growth is seldom observed experimentally in nc materials that are deformed under other deformation modes, ${ }^{4-8}$ although molecular dynamics simulation showed rapid grain growth in $\mathrm{nc} \mathrm{Cu}$ under severe cyclic load. ${ }^{9}$ Notably, nc Ni film produced by electrodeposition has been extensively used as a model material for studying fundamental mechanical behaviors of nc materials. ${ }^{8,10-18}$ In all cases, tensile tests were performed and no grain growth was reported, except at elevated temperatures. ${ }^{15}$ These observations seem to suggest that grain growth only occurs under some particular deformation modes. This raises the first issue: What is the critical condition for deformation to induce grain growth in a nc material?

It is well known that, during indentation, material under an indentor is subjected to heavy plastic deformation and extremely high stresses. ${ }^{19,20}$ The molecular dynamics simulation that demonstrated strain-induced grain growth used a large cyclic strain amplitude of $10 \%$ on $\mathrm{nc} \mathrm{Cu}$ with a grain size of $5.5 \mathrm{~nm} .{ }^{9}$ Therefore, it appears that heavy plastic strain under high stresses is a key factor for inducing grain growth.

If the above hypothesis is correct, another deformation mode, high-pressure torsion (HPT), ${ }^{21,22}$ should also result in grain growth in nc materials. HPT has been developed to refine coarse-grained (CG) metals and alloys into ultrafinegrained and nc materials. ${ }^{22-25}$ Indeed, it has been found to be capable of producing nc structures in $\mathrm{Cu}$ (Refs. 26 and 27)

a)Electronic mail: yzhu@lanl.gov and even amorphorizing TiNi alloys. ${ }^{28}$ These literature reports raise the second issue: If HPT can indeed induce grain growth in a nc material, is there an upper size limit for the grain growth? It is logical to assume that the upper size limit, if it exists, is the same as the minimum grain sizes produced by HPT refinement of the same material with an initial CG structure. If this assumption is true, it raises the third issue: Is there any difference between nc materials processed with HPT-induced grain growth and those produced by HPTinduced grain refinement?

It is the objective of this study to investigate the above three issues concerning the grain growth of nc materials induced by HPT. We choose electrodeposited (ED) Ni for this study because it has been extensively used as a model material for studying the deformation mechanisms and mechanical properties of nanomaterials. ${ }^{8,10-18}$ An ED Ni film with a thickness of $220 \mu \mathrm{m}$ was purchased from Goodfellow. Ni disks of $5 \mathrm{~mm}$ in diameter were processed by HPT for 5 revolutions under $7 \mathrm{GPa}$ at room temperature. The rotational speed was 1 revolution per minute. Any heat generated in the sample was quickly conducted away into the massive HPT anvils, and the temperature increase in the sample during HPT was expected to be minimal. For easy reference, the ED sample after further HPT processing is referred to as $\mathrm{ED}+\mathrm{HPT} \mathrm{Ni}$.

The ED Ni film has a columnar structure, with grains mostly equiaxed when viewed perpendicular to the film (Fig. 1). Twins were found frequently, and the dislocation density in the grain interior was measured from high-resolution electron microscopy (HRTEM) images as $1.2 \times 10^{16} \mathrm{~m}^{-2}$.

HPT led to significant grain growth [Fig. 2(a)]. Figure 2(b) shows a large grain with several subgrains. Figure 2(c) is an HRTEM image that shows a subgrain with many dis- 


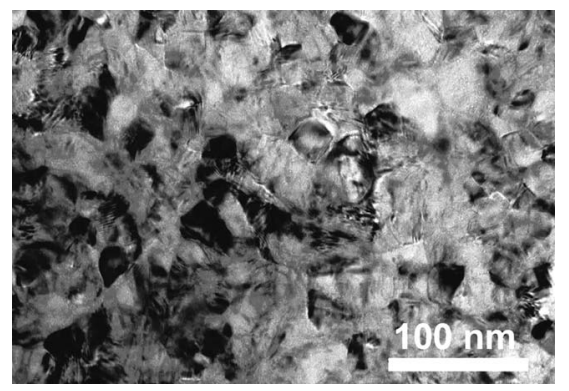

FIG. 1. Microstructure of nc electrodeposited Ni.

location cells. The white asterisks mark the subgrain boundary and the white dotted lines delineate the dislocation cell boundaries, which were drawn along dislocation walls revealed in the inverse Fourier transformation image (not shown here) of the Fig. 2(c). The dislocation density in the grain interior was measured from HRTEM images as about $2 \times 10^{16} \mathrm{~m}^{-2}$, higher than in the ED Ni. The higher dislocation density was apparently produced by the HPT deformation. In contrast, twins were rarely observed in the ED + HPT Ni, indicating that the HPT deformation significantly reduced the twin density.

Figures 3(a) and 3(b) show the grain size distributions of the ED Ni and the ED+HPT Ni, respectively. The grain sizes were measured from bright-field TEM images. As shown, the shapes of the distribution histograms are fairly similar, but

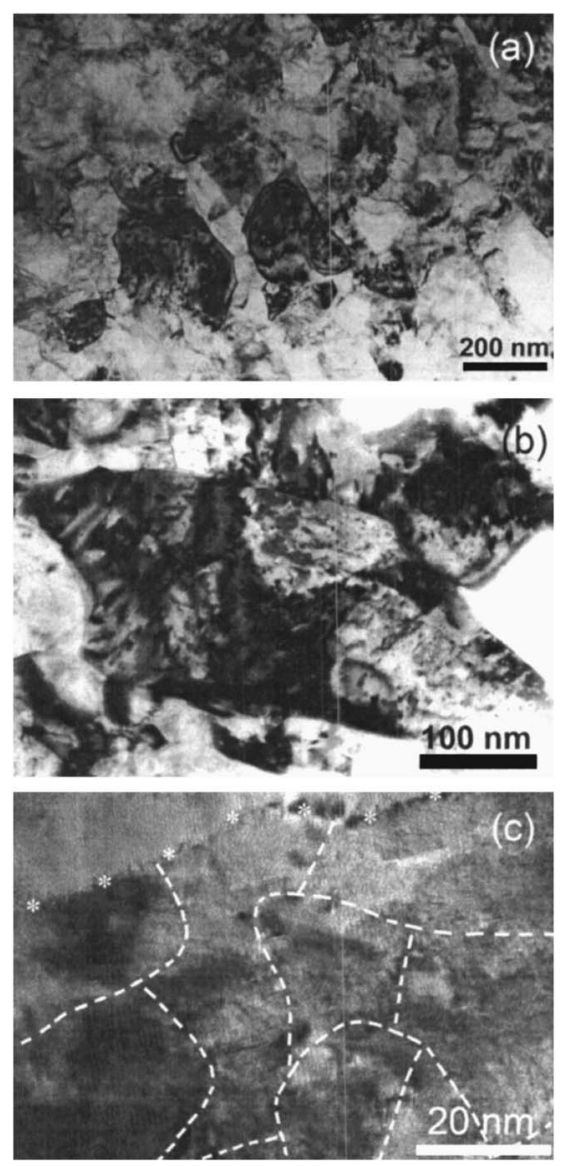

FIG. 2. Microstructure of electrodeposition+HPT Ni sample. (a) A TEM image showing nanostructures. (b) A large grain containing many subgrains. (c) A HRTEM image showing dislocation cells within a subgrain. The asterisks mark the subgrain boundary. The dotted lines mark the cell boundaries, which were determined by dislocation walls in an inverse Fourier transformed image of (c).
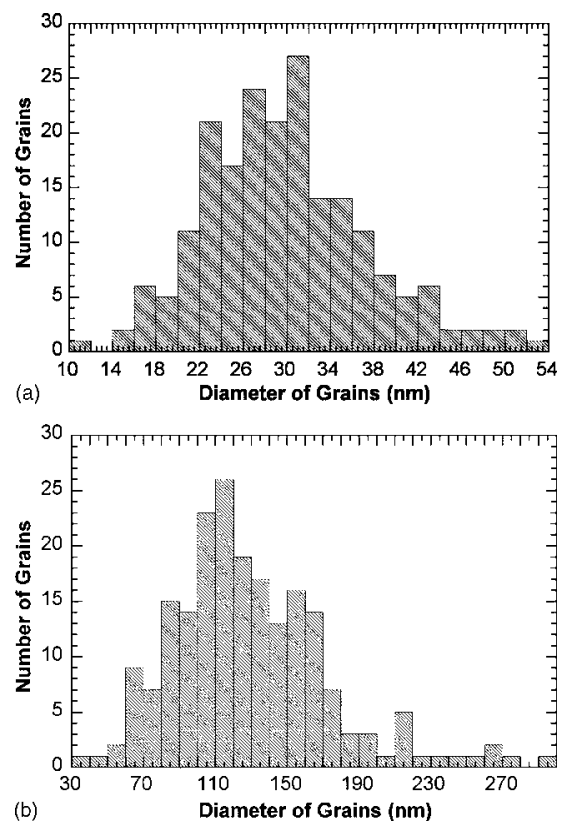

FIG. 3. The histogram of grain sizes of (a) electrodeposited nc Ni and (b) electrodeposition+HPT Ni sample.

the grain sizes are much bigger for the ED+HPT Ni sample. The mean grain size in the ED nc Ni is estimated from Fig. 3 (a) as $30 \pm 7.5 \mathrm{~nm}$, and further HPT processing increased the mean grain size to $129 \pm 43 \mathrm{~nm}$ [Fig. 3(b)]. Nanoindentations reveal that the grain growth led to a hardness decrease from 7.2 $\mathrm{GPa}$ in the $\mathrm{ED} \mathrm{Ni}$ to $6.1 \mathrm{GPa}$ after further HPT processing (ED+HPT).

Grain growth is a thermodynamically favorable process. ${ }^{3}$ However, the fact that nc ED Ni is stable at room temperature indicates that the system is at a local energy minima. The stability of nanostructures could also be affected by impurities in the sample. ${ }^{2} \mathrm{ED} \mathrm{Ni}$ is known to have relatively high impurities related to the electrodeposition process, ${ }^{12,16}$ and these impurities could have significantly stabilized the nc grain structure.

The HPT was performed under a pressure of $7 \mathrm{GPa}$ and it exerted an extremely high shear stress on the sample. The grain growth during HPT and nanoindentation, ${ }^{1-3}$ together with the lack of grain growth during tensile testing, ${ }^{10-14,16-18}$ suggest that the stress needs to be higher than a critical value to induce grain growth in nc materials, and tensile testing usually cannot generate stresses high enough to induce grain growth. Jin et al. ${ }^{3}$ observed grain-boundary migration in an in situ observation of indentation. According to an analytical model by Bobylev et al. ${ }^{29}$ low-angle grain boundaries can bow out from its equilibrium position under a high shear stress, and then dissociate when the stress reaches a critical value, leading to grain coalescence. High external shear stress can help overcome energy barriers associated with grain-boundary migration and grain coalescence.

Figure 3(b) reveals that the grains grew to $129 \pm 43 \mathrm{~nm}$ during the HPT, where $43 \mathrm{~nm}$ is the standard deviation. This value is near the lower end of the reported grain size range $(106-170 \mathrm{~nm})^{13,22,30-32}$ of HPT-processed CG Ni. This suggests that there is an upper size limit for deformationinduced grain growth, and this upper limit is close to the lower grain size limit for HPT refinement of CG Ni. The final grain size is determined by HPT parameters and material properties. ${ }^{33}$ In other words, the dynamic balance of the 


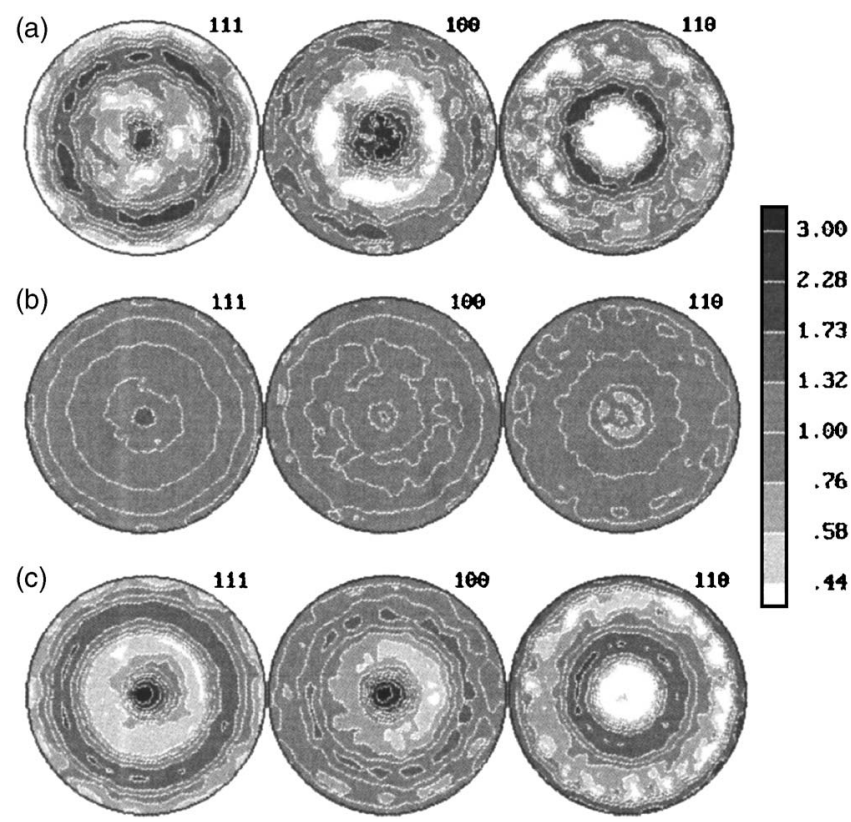

FIG. 4. The texture of (a) as-electrodeposited nc Ni, (b) electrodeposition $+\mathrm{HPT} \mathrm{Ni}$, and (c) nc Ni produced by HPT processing of CG Ni. Equal-area projection pole figures displayed with normal direction aligned with either growth direction (a) or HPT compression axis [(b) and (c)].

grain growth process and the grain refinement process determines the final grain size. The higher impurity content of ED $\mathrm{Ni}$ should lead to finer final grain sizes, ${ }^{34}$ which could explain why the grain size of the ED+HPT sample is near the lower end of the reported grain size range. The duration of HPT processing in this study was $5 \mathrm{~min}$. We expect the upper limit of grain size to increase if the HPT process is performed for a longer duration or at a lower strain rate, similar to the scenario in a systematic nanoindentation study by Zhang et al. ${ }^{1,2}$ Further study is needed to verify this point.

The microstructure of the ED+HPT Ni (Fig. 2) has some similarities with that of CG Ni processed by HPT under the same conditions. ${ }^{13,22,30-32}$ These observations on microstructures and grain sizes make one wonder if the ED Ni was deformed by the same mechanisms as the CG Ni during HPT. This can be checked by textures in the HPT-processed samples, because the deformation mechanisms directly affect texture evolution.

The pole measured by x-ray diffraction (Fig. 4) indicate that the ED Ni has a duplex $<111>/<001>$ fiber texture. Subsequent HPT processing $(\mathrm{ED}+\mathrm{HPT} \mathrm{Ni})$ resulted in a nearly random texture. The nc Ni produced by HPT processing of CG Ni displays a duplex $<111>/<001>$ texture that is consistent with simple-shear texture evolution in fcc metals produced by dislocation slip. These results suggest that grain boundary processes played a significant role in the deformation of the ED Ni during the HPT process. This is consistent with the in situ TEM observation that suggested that the deformation-induced grain growth is associated with grain rotation, grain boundary migration, and grain coalescence. $^{3}$ Note also that the non-equilibrium grain boundaries generated during HPT should have high mobility, which helps with grain growth. ${ }^{35}$

In summary, HPT processing resulted in grain growth in $\mathrm{nc} \mathrm{ED} \mathrm{Ni}$ at room temperature. It appears that there is a critical stress value above which deformation-induced grain growth would occur. There is an upper limit at which the deformation-induced grain growth in nc Ni wili stop, and the mean grain size will remain unchanged with further HPT strain. This upper grain size limit is close to the lower grain size limit for HPT refinement of CG Ni. During the HPT process, the nc ED Ni was deformed primarily by grainboundary processes, including grain rotation, in contrast to the sample with initial CG structure, which deformed by dislocation slip.

${ }^{1}$ K. Zhang, J. R. Weertman, and J. A. Eastman, Appl. Phys. Lett. 85, 5197 (2004)

${ }^{2}$ K. Zhang, J. R. Weertman, and J. A. Eastman, Appl. Phys. Lett. 87, 061921 (2005).

${ }^{3}$ M. Jin, A. M. Minor, E. A. Stach, and J. W. Morris, Jr., Acta Mater. 52, 5381 (2004).

${ }^{4}$ R. Z. Valiev, I. V. Alexandrov, Y. T. Zhu, and T. C. Lowe, J. Mater. Res. 5, 17 (2002).

${ }^{5}$ X. Zhang, H. Wang, R. O. Scattergood, J. Narayan, C. C. Koch, A. V. Sergueeva, and A. K. Mukherjee, Appl. Phys. Lett. 81, 823 (2002).

${ }^{6}$ Y. M. Wang, E. Ma, R. Z. Valiev, and Y. T. Zhu, Adv. Mater. (Weinheim, Ger.) 16, 328 (2004).

${ }^{7}$ Y. M. Wang, M. W. Chen, F. Zhou, and E. Ma, Nature (London) 419, 912 (2002).

${ }^{8}$ Z. W. Shan, E. A. Stach, J. M. K. Wiezorek, J. A. Knap, D. M. Follstaedt, and S. X. Mao, Nature (London) 305, 654 (2004).

${ }^{9}$ J. Schiøtz, Mater. Sci. Eng., A 375, 975 (2004).

${ }^{10}$ Z. Budrovic, H. Van Swygenhoven, P. M. Derlet, S. Van Petegem, and B. Schmitt, Science 309, 273 (2004).

${ }^{11}$ F. D. Torre, H. Van Swygenhoven, and M. Victoria, Acta Mater. 50, 3957 (2002).

${ }^{12}$ F. D. Torre, H. Van Swygenhoven, R. Schäublin, P. Spätig, and M. Victoria, Scr. Mater. 53, 23 (2005).

${ }^{13}$ F. D. Torre, P. Spätig, R. Schäublin, and M. Victoria, Acta Mater. 53, 2337 (2005).

${ }^{14}$ K. S. Kumar, S. Suresh, M. F. Chisholm, J. A. Horton, and P. Wang, Acta Mater. 51, 387 (2003).

${ }^{15}$ S. X. McFadden, R. S. Mishra, R. Z. Valiev, A. P. Zhilyaev, and A. K. Mukherjee, Nature (London) 398, 684 (1999).

${ }^{16}$ Y. M. Wang, S. Cheng, Q. M. Wei, E. Ma, T. G. Nieh, and A. Hamaza, Scr. Mater. 51, 1023 (2004).

${ }^{17}$ H. Li and F. Ebrahimi, Appl. Phys. Lett. 84, 4307 (2004).

${ }^{18}$ F. Ebrahimi, Z. Ahmed, and H. Li, Appl. Phys. Lett. 85, 3749 (2004).

${ }^{19}$ J. M. Molina-Aldareguia, S. J. Lloyd, M. Oden, T. Joelsson, L. Hultman, and W. J. Clegg, Philos. Mag. B 82, 1983 (2002).

${ }^{20}$ J. E. Bradby, J. S. Williams, J. Wong-Leung, M. V. Swain, and P. Munroe, Appl. Phys. Lett. 78, 3235 (2001).

${ }^{21}$ R. Z. Valiev, R. K. Islamgaliev, and I. V. Alexandrov, Prog. Mater. Sci. 45, 103 (2000).

${ }^{22}$ A. P. Zhilyaev, G. V. Nurislamova, B. K. Kim, M. D. Baró, J. A. Szpunar, and T. G. Langdon, Acta Mater. 51, 753 (2003).

${ }^{23}$ Y. T. Zhu and D. P. Butt, In Encyclopedia of Nanotechnology, edited by $\mathrm{H}$.

S. Nalwa (American Scientific, Stevenson Ranch, CA, 2004), Vol. 6, p. 843.

${ }^{24}$ Y. T. Zhu and T. G. Langdon, JOM 56, 58 (2004).

${ }^{25}$ H. Jiang, Y. T. Zhu, D. P. Butt, I. V. Alexandrov, and T. C. Lowe, Mater. Sci. Eng., A 290, 128 (2000).

${ }^{26}$ X. Z. Liao, Y. H. Zhao, Y. T. Zhu, R. Z. Valiev, and D. V. Gunderov, J. Appl. Phys. 96, 636 (2004).

${ }^{27}$ X. Z. Liao, Y. H. Zhao, S. G. Srinivasan, Y. T. Zhu, R. Z. Valiev, and Gunderov, Appl. Phys. Lett. 84, 592 (2004).

${ }^{28}$ J. Y. Huang, Y. T. Zhu, X. Z. Liao, and R. Z. Valiev, Philos. Mag. Lett. 84, 183 (2004).

${ }^{29}$ S. V. Bobylev, M. Y. Gutkin, and I. A. Ovid'ko, Acta Mater. 52, 3793 (2004).

${ }^{30}$ N. Krasilnikov, W. Lojkowski, Z. Pakiela, and R. Z. Valiev, Mater. Sci. Eng., A 397, 330 (2005).

${ }^{31}$ A. P. Zhilyaev, S. Lee, G. V. Nurislamova, R. Z. Valiev, and T. G. Langdon, Scr. Mater. 44, 2753 (2001).

${ }^{32}$ A. P. Zhilyaev, B. K. Kim, G. V. Nurislamova, M. D. Baró, J. A. Szpunar, and T. G. Langdon, Scr. Mater. 46, 575 (2002).

${ }^{33}$ F. A. Mohamed, Acta Mater. 51, 4107 (2003).

${ }^{34}$ S. X. McFadden and A. K. Mukherjee, Mater. Sci. Eng., A 395, 265 (2005).

${ }^{35}$ J. Lian, R. Z. Valiev, and B Baudelet, Acta Metall. Mater. 43, 4165 (1995). 